\title{
Au as an efficient promoter for electrocatalytic oxidation of formic acid and carbon monoxide: a comparison between Pt-on-Au and PtAu alloy catalysts
}

\author{
Qiang Zhang • Ruirui Yue • Fengxing Jiang • \\ Huiwen Wang • Chunyang Zhai • Ping Yang • Yukou Du \\ Published online: 19 July 2013 \\ (C) The Author(s) 2013. This article is published with open access at SpringerLink.com
}

\begin{abstract}
The absence of unpaired d-electrons of gold leads to its lack of reactivity and paucity of catalytic activity. Synergistic activity of bimetallic PtAu has been proved, and its structure greatly influences on the electrocatalytic activity toward formic acid and carbon monoxide oxidation. Here, a comparison between Pt-modified Au (designated as Pt-on-Au) and PtAu alloy catalysts has been studied. The Pt-on-Au catalyst was prepared by electrodeposition of $\mathrm{Pt}$ on the pre-prepared $\mathrm{Au}$, while PtAu alloy was obtained by co-electrodeposition. As a whole, both types of PtAu catalysts were found to be more active toward formic acid electrooxidation compared to pure $\mathrm{Pt}$, exhibiting maximum activity on Pt-on-Au catalyst with $\mathrm{Pt}$ to Au atomic ratio of $1: 10.22$. Moreover, the $\mathrm{Pt} / \mathrm{Au}$ atomic ratio directly relates to the oxidation pathway of formic acid and carbon monoxide oxidation. The results may be ascribed to much less $\mathrm{CO}_{\mathrm{ads}}$ on the surface than single Pt catalyst due to the effect of $\mathrm{Au}$ nanoparticles. $\mathrm{CO}$ stripping voltammograms present the obvious variation between Pt-on-Au and PtAu alloy catalysts. Meanwhile, the electrocatalytic activities of bimetallic PtAu are evaluated by electrochemical impedance spectroscopy and Tafel analysis.
\end{abstract}

Keywords Pt-on-Au catalyst $\cdot$ PtAu alloy $\cdot$ Electrocatalytic activity $\cdot$ Formic acid $\cdot$ CO stripping voltammograms

\section{Introduction}

In order to solve the problems of air pollution, increasing energy demands, as well as limited fuel reserves caused by

Q. Zhang $\cdot$ R. Yue $\cdot$ F. Jiang $(\bowtie) \cdot H$. Wang $\cdot$ C. Zhai $\cdot$ P. Yang $\cdot$

Y. Du $(\triangle)$

College of Chemistry, Chemical Engineering and Materials

Science, Soochow University, Suzhou 215123,

People's Republic of China

e-mail: jiangfx82@163.com

e-mail: duyk@suda.edu.cn traditional fuel consuming, energy storage devices including fuel cells become more and more concerned [1-7]. In particular, direct formic acid fuel cell (DFAFC) has attracted great attention with its advantages of nontoxicity and low fuel crossover as compared to methanol, which makes DFAFC a promising candidate for power source in portable electronic devices [8, 9]. As we have known, a catalyst is a very important part of fuel cells, and platinum is the most common anode catalyst for formic acid (FA) oxidation. However, $\mathrm{Pt}$ is prone to poisoning by CO-like intermediates, leading to a significant decrease of catalytic performance [10-12]. It is due to the fact that the indirect pathway by dehydration is predominant in the oxidation reaction of FA on pure Pt, but not by the dehydrogenation pathway [13].

In order to improve the catalytic performance of FA oxidation by dehydrogenation pathway, the development of bimetallic $\mathrm{Pt}-\mathrm{M}(\mathrm{M}=\mathrm{Au}, \mathrm{Pd}, \mathrm{Ru}, \mathrm{Bi}$, etc. $)$ catalysts has been recognized as one of the most effective strategies. The facts show that a Pt-based catalyst has improved the catalytic performance of FA oxidation compared with pure $\mathrm{Pt}$ [14-19]. Among various Pt-based catalysts, bimetallic Pt$\mathrm{Au}$ is one of the best catalysts for formic acid oxidation, which is attributed to its enhanced activity $[11,20,21]$ and stability against dissolution by raising the Pt oxidation potential [20, 22-26]. Moreover, the incorporation of $\mathrm{Au}$ into $\mathrm{Pt}$ could lead to the segregation of $\mathrm{Pt}$ sites and further reduce the number of adsorption sites for $\mathrm{CO}$, thereby yielding an improvement in the activity of FA oxidation [13, 20, 27].

Recently, various bimetallic Pt-Au catalysts with different structures, such as PtAu alloy [21, 28], Pt-modified Au (Pt-on-Au) [29, 30], and Au@Pt [31, 32], show excellent catalytic activity toward FA oxidation. Park et al. [33] found that the uniform Pt-on-Au nanoparticles showed higher electrocatalytic activities than the pure Pt electrocatalyst in the area- and mass-specific current densities. It is attributed to the enhancement effect of $\mathrm{Au}$ atoms and the high Pt utilization in the FA electrooxidation reaction. Ding et al. [29] 
Table 1 Preparation variables and composition of Pt-on-Au catalysts

\begin{tabular}{|c|c|c|c|c|c|}
\hline \multirow[t]{2}{*}{ Catalysts } & \multicolumn{2}{|c|}{ Precursor concentration $/ \mathrm{mmol} \mathrm{L}^{-1}$} & \multicolumn{2}{|l|}{$Q_{\mathrm{dep}} / \mathrm{C}$} & \multirow{2}{*}{$\frac{\text { Atomic ratio }^{\mathrm{a}}}{\mathrm{Pt} / \mathrm{Au}}$} \\
\hline & $\mathrm{HAuCl}_{4}$ & $\mathrm{H}_{2} \mathrm{PtCl}_{6}$ & $\mathrm{Au}$ & $\mathrm{Pt}$ & \\
\hline M-1:20.01 & 3.0 & 0.77 & $5 \times 10^{-2}$ & $5 \times 10^{-5}$ & $1: 20.01$ \\
\hline M-1:10.22 & 3.0 & 0.77 & $5 \times 10^{-2}$ & $1 \times 10^{-4}$ & $1: 10.22$ \\
\hline M-1:7.16 & 3.0 & 0.77 & $5 \times 10^{-2}$ & $2 \times 10^{-4}$ & $1: 7.16$ \\
\hline M-1:5.28 & 3.0 & 0.77 & $5 \times 10^{-2}$ & $5 \times 10^{-4}$ & $1: 5.28$ \\
\hline M-1:2.19 & 3.0 & 0.77 & $5 \times 10^{-2}$ & $1 \times 10^{-3}$ & $1: 2.19$ \\
\hline Pure Pt & - & 0.77 & - & $1 \times 10^{-2}$ & - \\
\hline
\end{tabular}

${ }^{\mathrm{a}}$ The atomic ratio on the surface of catalyst obtained by EDX

fabricated the monolayer Pt-modified nanoporous Au catalyst with ultralow Pt loading, great tolerance to poisoning, and high stability for FA electooxidation. They suggested that the outmost Au layer may not only inhibit Pt oxidation but also hold a themodynamic stabilization effect. $\mathrm{Xu}$ and co-workers [21] studied the electrocatalytic activity of PtAu alloy nanoparticles with 1:1 atomic ratio and demonstrated that the $\mathrm{PtAu} / \mathrm{C}$ catalyst exhibited a higher activity for FA oxidation reaction than commercial Pt/C. Liu et al. [34] developed a 3D porous AuPt alloy foam film catalyst with superior electrocatalytic activity toward FA oxidation. Huang et al. [35] prepared a PtAu alloy catalyst by electrodeposition method for FA electrooxidation with the dehydration pathway. Additionally, the surface composition of atomic $\mathrm{Pt} / \mathrm{Au}$ ratio and the preparation method are significantly related to the electrocatalytic activity of bimetallic PtAu catalyst for FA oxidation reaction [13, 34-36]. In general, the high electrocatalytic activity of bimetallic PtAu catalyst has been ascribed to the special electronic effect [29, 36, 37], ensemble effect $[11,20,30]$, and synergistic effect $[34,38$, 39]. Many research findings have revealed that both Pt-on$\mathrm{Au}$ and PtAu alloy catalysts exhibited high electrocatalytic activity toward FA oxidation with much less $\mathrm{CO}_{\mathrm{ads}}$ than that on Pt catalyst surface. However, to the best of our knowledge, there are no reports on the comparison of electrocatalytic activity of Pt-on-Au and PtAu alloy obtained by electrodeposition toward FA and CO oxidation.

In this work, we synthesized two types of bimetallic PtAu catalysts by electrodeposition of $\mathrm{Pt}$ on pre-prepared $\mathrm{Au}$ nanoparticle (designated as Pt-on-Au) and co-deposition of $\mathrm{Pt}$ and $\mathrm{Au}$ (designated as PtAu alloy). The electrocatalytic activities of bimetallic PtAu catalysts with a different $\mathrm{Pt} / \mathrm{Au}$ ratio toward FA and $\mathrm{CO}$ oxidation were investigated systematically by cyclic voltammetry, Tafel plots, and electrochemical impedance spectroscopy (EIS).

\section{Materials and methods}

\section{Materials}

$\mathrm{H}_{2} \mathrm{PtCl}_{6}$ and $\mathrm{HAuCl}_{4}$ were purchased from Sinopharm Chemicals Reagent Co., Ltd., China. All chemicals (HCOOH and $\mathrm{H}_{2} \mathrm{SO}_{4}$ ) were of analytical grade. All aqueous solutions were prepared with double-distilled water.

Table 2 Preparation variables and composition of PtAu alloy catalysts

\begin{tabular}{|c|c|c|c|c|}
\hline \multirow[t]{2}{*}{ Catalysts } & \multicolumn{2}{|c|}{ Precursor concentration $\mathrm{a} / \mathrm{mmol} \mathrm{L}^{-1}$} & \multirow{2}{*}{$\frac{Q_{\mathrm{dep}} / \mathrm{C}}{\mathrm{PtAu}^{\mathrm{c}}}$} & \multirow{2}{*}{$\frac{\text { Atomic ratio }^{\text {b }}}{\mathrm{Pt} / \mathrm{Au}}$} \\
\hline & $\mathrm{HAuCl}_{4}$ & $\mathrm{H}_{2} \mathrm{PtCl}_{6}$ & & \\
\hline A-5.08:1 & 2.5 & 0.5 & $5 \times 10^{-3}$ & $5.08: 1$ \\
\hline A-3.44:1 & 2.25 & 0.75 & $5 \times 10^{-3}$ & $3.44: 1$ \\
\hline A- $0.94: 1$ & 1.5 & 1.5 & $5 \times 10^{-3}$ & 0.94:1 \\
\hline$\backslash \mathrm{A}-1: 2.04$ & 1.0 & 2.0 & $5 \times 10^{-3}$ & $1: 2.04$ \\
\hline A-1:2.70 & 1.0 & 2.0 & $5 \times 10^{-3}$ & $1: 2.07$ \\
\hline A-1:3.85 & 0.75 & 2.25 & $5 \times 10^{-3}$ & $1: 3.85$ \\
\hline
\end{tabular}

${ }^{\mathrm{a}} \mathrm{A}$ mixed solution containing $\mathrm{HAuCl}_{4}$ and $\mathrm{H}_{2} \mathrm{PtCl}_{6}$

${ }^{\mathrm{b}}$ The atomic ratio on the surface of catalyst obtained by EDX

${ }^{\mathrm{c}}$ The total deposited charge for PtAu alloy 
Fig. 1 SEM images of M-

$1: 10.22$ (a) and A-1:2.04 (b)

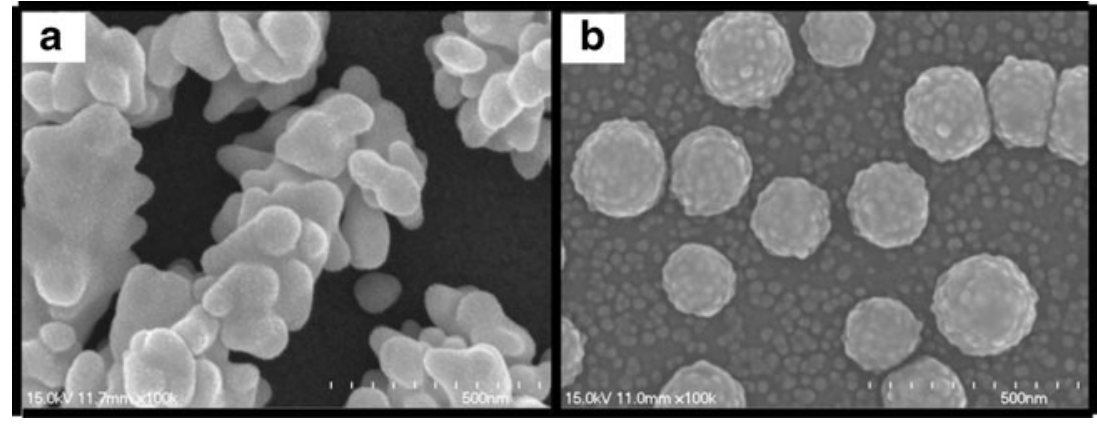

Apparatus

The electrochemical experiments were carried out in a conventional three-electrode cell using a CHI660B electrochemical workstation (Shanghai Chenhua Instrumental Co., Ltd., China). A glassy carbon electrode (GCE, $3 \mathrm{~mm}$ in diameter) was used as the working electrode. Before use, GCE surface was polished with $0.3 \mu \mathrm{m}$ alumina slurry and then rinsed with doubly distilled water in ultrasonic bath. The counter electrode and the reference electrode were platinum wire and saturated calomel electrode, respectively, which were carefully cleared before the experiment. Electrolyte solutions were deaerated by a dry nitrogen stream and maintained with a slight overpressure of nitrogen during the electrochemical measurements. All of the electrochemical measurements were carried out at room temperature. Scanning electron microscope (SEM, S-4700, Japan) equipped with an energydispersive X-ray analyzer (EDX, S-4700, Japan) was used to determine the morphology and composition of catalysts. Xray diffraction (XRD) measurements and X-ray photoelectron spectroscopy (XPS) were performed on an X'Pert-Pro MPD $\mathrm{X}$-ray diffractometer using $\mathrm{CuKa}$ radiation $(50 \mathrm{kV})$ and on an ESCALab220i-XL electron spectrometer from VG Scientific using 300-W AlKa radiation, respectively.

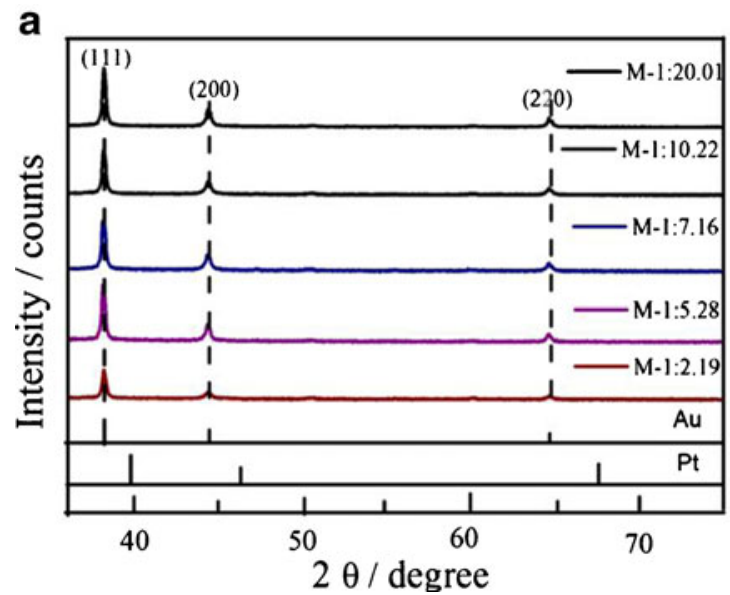

Preparation of the catalysts

The procedures of Pt-on-Au nanoparticles were prepared by a two-step electrodeposition. First, the Au-modified GCE $(\mathrm{Au} / \mathrm{GCE})$ were obtained by the electrodeposition of $\mathrm{Au}$ on GCE at $-0.2 \mathrm{~V}$ in a solution consisting of $3.0 \mathrm{mM} \mathrm{HAuCl}_{4}$ and $0.5 \mathrm{M} \mathrm{H}_{2} \mathrm{SO}_{4}$ and then was rinsed with double-distilled water for the following experiment use. The pre-prepared $\mathrm{Au} / \mathrm{GCE}$ as working electrode was immersed into $0.5 \mathrm{M}$ $\mathrm{H}_{2} \mathrm{SO}_{4}$ solution containing $0.77 \mathrm{mM} \mathrm{H}_{2} \mathrm{PtCl}_{6}$ for the electrodeposition of $\mathrm{Pt}$. Pt nanoparticles were deposited under an applied potential of $-0.2 \mathrm{~V}$ by a potentiostatic method. The resultant $\mathrm{Pt}$-modified $\mathrm{Au} / \mathrm{GCE}$ (Pt-on-Au) was rinsed thoroughly with double-distilled water several times. The $\mathrm{Pt}-\mathrm{Au}$ catalysts with different atomic ratios on the surface of catalysts by controlling the deposited charge of Pt are designated as M-1:20.01, M-1:10.22, M-1:7.16, M-1:5.28, and M1:2.19 in Table 1. For the preparation of PtAu alloy catalysts, it was completed by co-deposition at a constant applied potential of $-0.2 \mathrm{~V}$ in a mixed $\mathrm{H}_{2} \mathrm{PtCl}_{6} / \mathrm{HAuCl}_{4}$ solution containing $0.5 \mathrm{M} \mathrm{H}_{2} \mathrm{SO}_{4}$. The different atomic ratios of PtAu alloy were prepared by changing the concentration of $\mathrm{H}_{2} \mathrm{PtCl}_{6}$ and $\mathrm{HAuCl}_{4}$, and the corresponding samples were designed as A-5.08:1, A-3.44:1, A-0.94:1, A-1:2.04, A-

b

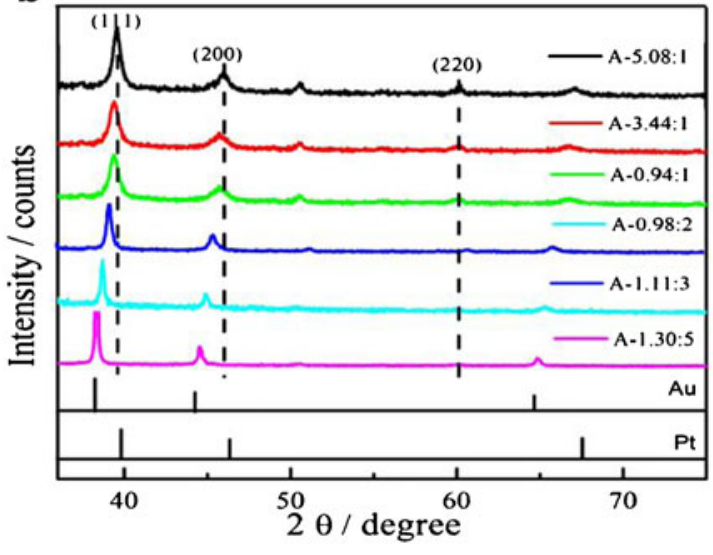

Fig. 2 XRD patterns of Pt-on-Au and PtAu alloy nanoparticles: a Pt-on-Au nanoparticles, b PtAu alloy nanoparticles 


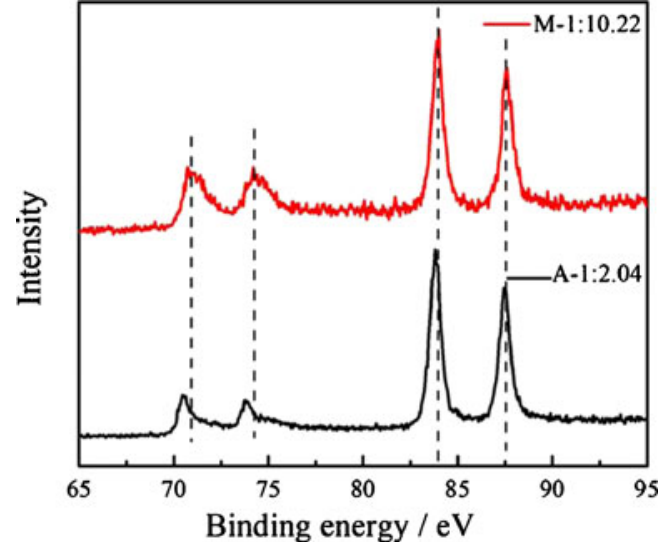

Fig. 3 XPS spectra of $\mathrm{Pt}_{4 \mathrm{f}}$ and $\mathrm{Au}_{4 \mathrm{f}}$ for the M-1:10.22 and A-1:2.04

1:3.27, and A-1:3.85 in Table 2, respectively. For a comparison of voltammetric features and electrocatalytic activities, the pure Pt catalyst on GCE (Pt/GCE) was also prepared under similar conditions as stated earlier.

Pt or Au loading was evaluated by the charge integrated during the deposition process $\left(Q_{\text {dep }}\right)$ with an assumption of $100 \%$ current efficiency according to Eq. (1):

$W=\frac{\eta Q_{\mathrm{dep}} M}{F Z}$

Here, $W$ is the mass of deposited $\mathrm{Pt}$ or $\mathrm{Au}, \eta$ is current efficiency (assuming $100 \%$ current efficiency here), $Q_{\text {dep }}$ is the total charge passed through the electrodes during the deposition process, $M$ is the molecular weight, $F$ is the Faraday constant $\left(96,485 \mathrm{C} \mathrm{mol}^{-1}\right)$, and $Z$ is the number of electrons transferred (taken as four for the $\mathrm{Pt}$ and three for the $\mathrm{Au}$ formation).

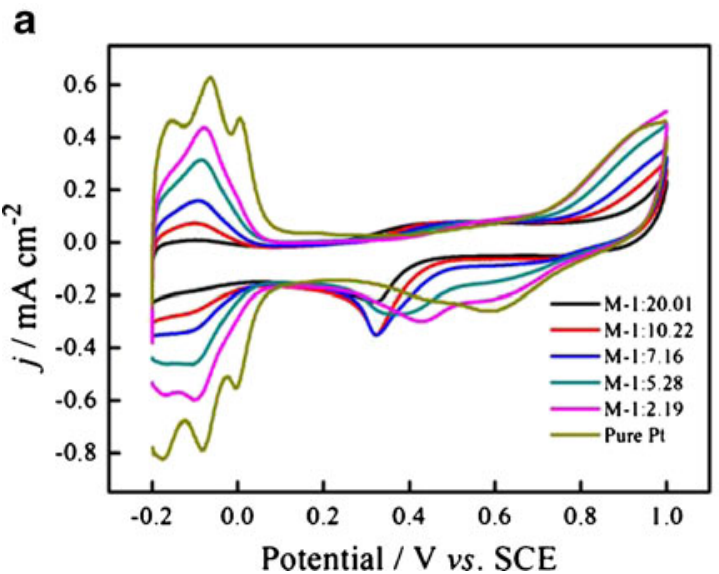

\section{Results and discussion}

Morphology and structure characterization

The morphology and structural features of the two types of PtAu catalysts were investigated by SEM and XRD. Figure 1 shows a SEM micrograph for the M-1:10.22(A) and A1:2.04(B) on GC electrode. As can be seen from Fig. 1a, the M-1:10.22 catalyst formed with Pt particles growing layer by layer on the surface of pre-deposited $\mathrm{Au}$ substrate exhibits rough surface morphology and coral-like structure. However, the A-1:2.04 shown in Fig. 1b displays a quasispherical particle structure with small pricks uniformly dispersing on the surface, which is the nucleation site for the alloy deposition. Figure 2 shows the XRD patterns of the two types of as-prepared PtAu catalysts. As is known, the peaks of pure gold nanoparticles $\left(2 \theta=38.2^{\circ}, 44.4^{\circ}\right.$, and $\left.64.6^{\circ}\right)$ and pure platinum nanoparticles $\left(2 \theta=39.8^{\circ}, 46.2^{\circ}\right.$, and $\left.67.5^{\circ}\right)$ are assigned to the (111), (200), and (220) planes, respectively, indicating the typical face-centered-cubic crystal structure. As shown in Fig. 2a, besides the diffraction peaks of Au, no obvious reflection peaks of Pt can be observed due to the low loading of $\mathrm{Pt}$ on the Au surface, also indicating that the Pt nanoparticles are uniformly deposited on Au surface without agglomeration. In Fig. 2b, it is worth noting that the (111) peaks of PtAu alloy occur between (111) peaks of pure $\mathrm{Au}$ and $\mathrm{Pt}$ nanoparticles, which move to a lower $2 \theta$ value tending towards the corresponding peak of pure $\mathrm{Au}$ as the $\mathrm{Pt} / \mathrm{Au}$ ratio decreases. It suggests that a single-phase alloy of PtAu has been formed by electrochemical co-deposition. In addition, the EDX analysis in Tables 1 and 2 has also confirmed the presence of $\mathrm{Pt}$ and $\mathrm{Au}$ in the as-prepared Pt-on-Au and PtAu alloy catalysts.

To investigate the atomic composition and properties of M-1:10.22 and A-1:2.04, XPS was then used to characterize

b

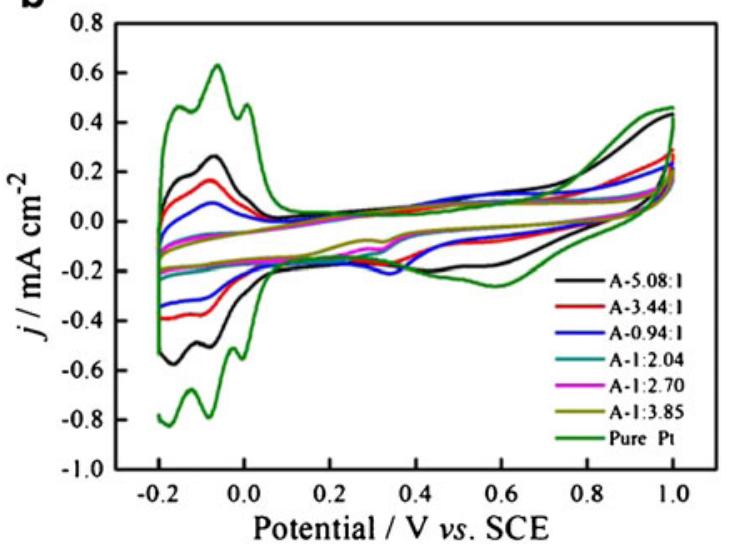

Fig. 4 a CVs of Pt/GC and Pt-on-Au electrodes and $\mathbf{b} \mathrm{Pt} / \mathrm{GC}$ and PtAu alloy electrodes recorded in $0.5 \mathrm{M} \mathrm{H}_{2} \mathrm{SO}_{4}$ aqueous solution. Scan rate, $50 \mathrm{mV} \mathrm{s}^{-1}$ 
a

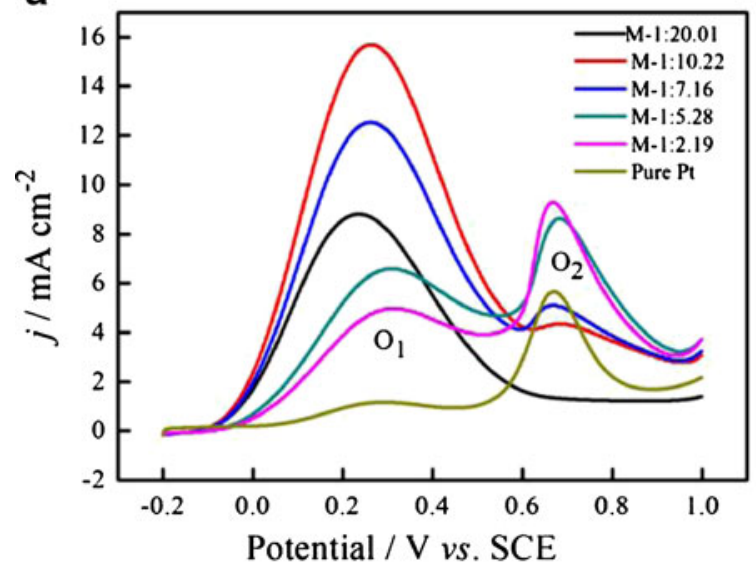

C

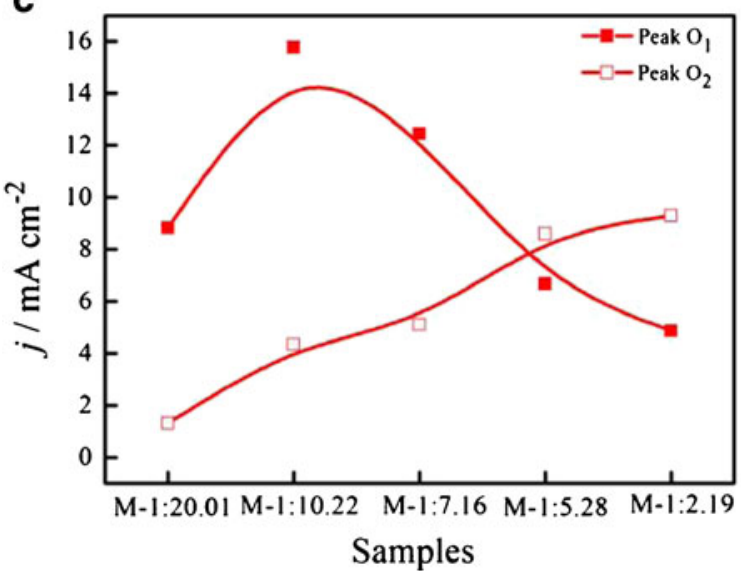

Fig. 5 a CVs of Pt/GC and Pt-on-Au electrodes. b PtAu alloy and Pt/ GC electrodes in $0.5 \mathrm{M} \mathrm{HCOOH}+0.5 \mathrm{M} \mathrm{H}_{2} \mathrm{SO}_{4}$ solution only the positive-going potential scans at $50 \mathrm{mV} \mathrm{s}^{-1}$ and current densities of

these samples. As shown in Fig. 3, for M-1:10.22, the peaks at 74.1 and $70.9 \mathrm{eV}$ correspond to the $4 \mathrm{f}_{5 / 2}$ and $4 \mathrm{f}_{7 / 2}$ of b

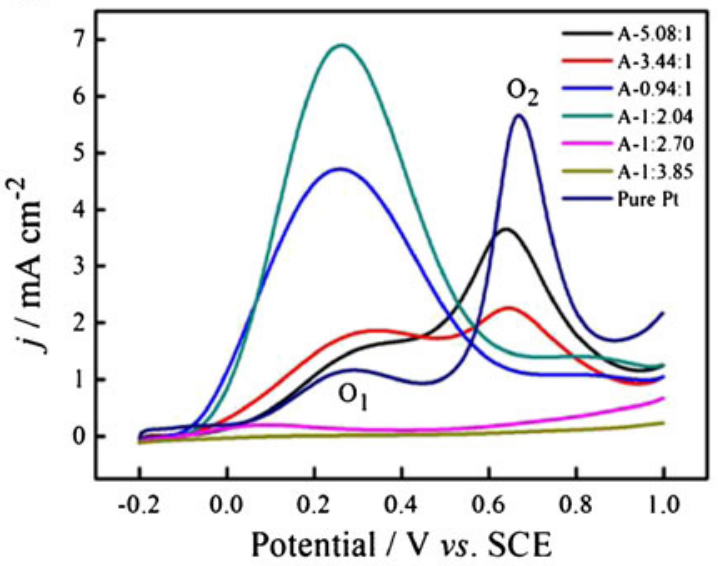

d

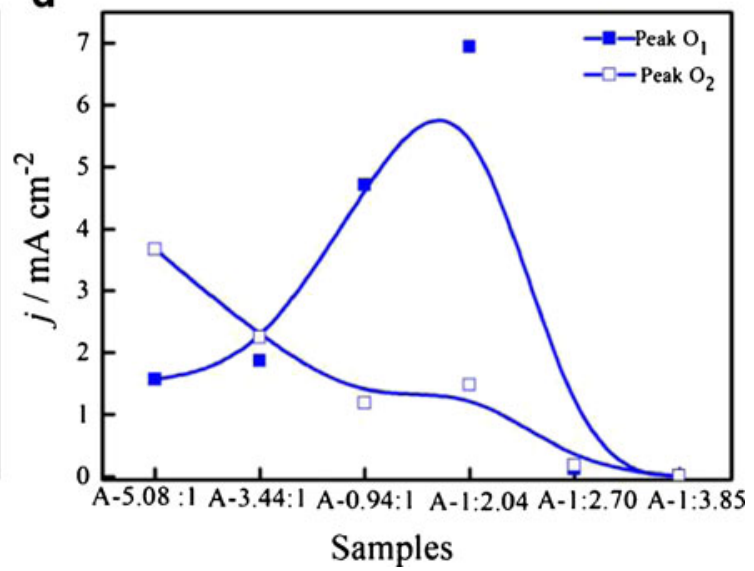

peak $\mathrm{O}_{1}$ and the peak $\mathrm{O}_{2}$ in $\mathrm{HCOOH}$ oxidation on Pt-on-Au electrodes (c) and on PtAu alloy electrodes (d) as a function of sample compositions

metallic Pt, which shift slightly to lower binding energy as compared to bulk Pt (74.5 and $71.2 \mathrm{eV})$ [40], indicating that

Table 3 Parameters of FA oxidation and CO stripping voltammograms on the Pt-on-Au and PtAu alloy catalysts, respectively

\begin{tabular}{|c|c|c|c|c|c|c|}
\hline \multirow[t]{2}{*}{ Catalysts } & \multicolumn{3}{|l|}{ FA oxidation } & \multicolumn{3}{|c|}{ CO stripping } \\
\hline & $j_{\mathrm{O} 1} \mathrm{~mA} \mathrm{~cm}^{-2}$ & $j_{\mathrm{O} 2} \mathrm{~mA} \mathrm{~cm}{ }^{-2}$ & $j_{\mathrm{O} 1} / j_{\mathrm{O} 2}$ & $E_{\mathrm{I}} \mathrm{V}$ & $E_{\mathrm{II}} \mathrm{V}$ & $Q_{\mathrm{CO}} \mathrm{C}$ \\
\hline M-1:20.01 & 8.82 & 1.30 & 6.78 & 0.671 & 0.84 & 0.013 \\
\hline M-1:10.22 & 15.76 & 4.33 & 3.64 & 0.682 & - & 0.062 \\
\hline M-1:7.16 & 12.44 & 5.10 & 2.44 & 0.688 & - & 0.052 \\
\hline M-1:5.28 & 6.67 & 8.59 & 0.78 & 0.693 & - & 0.043 \\
\hline M-1:2.19 & 4.86 & 9.29 & 0.52 & 0.689 & 1.10 & 0.067 \\
\hline A-5.08:1 & 1.57 & 3.67 & 0.43 & 0.71 & - & 0.097 \\
\hline A-3.44:1 & 1.87 & 2.25 & 0.83 & 0.73 & 1.10 & 0.034 \\
\hline A-0.94:1 & 4.71 & 1.19 & 3.97 & 0.76 & 1.07 & 0.010 \\
\hline A-1:2.04 & 6.94 & 1.48 & 4.69 & 0.84 & 1.04 & 0.008 \\
\hline A-1:2.70 & 0.13 & 0.18 & 0.72 & - & 1.01 & - \\
\hline A-1:3.85 & - & - & - & - & 1.01 & - \\
\hline Pure Pt & 1.13 & 5.56 & 0.20 & 0.660 & 0.97 & 0.136 \\
\hline
\end{tabular}



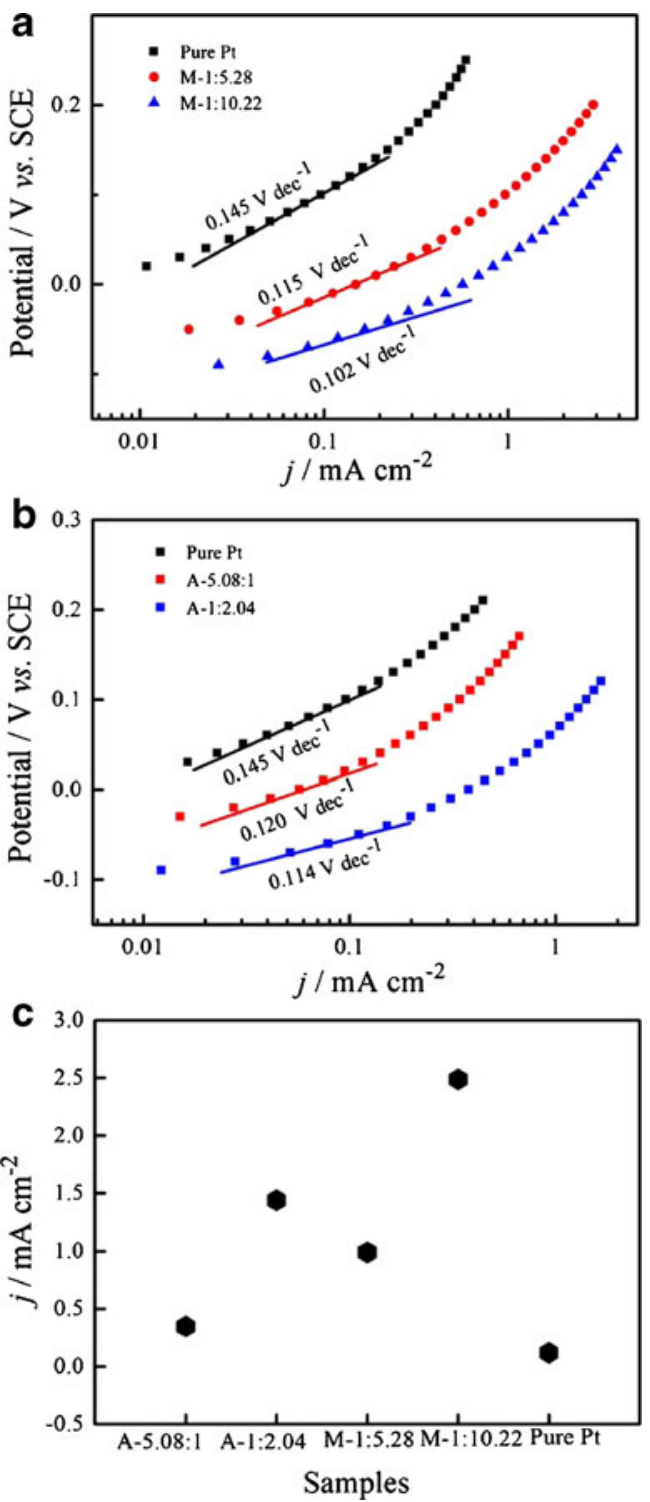

Fig. 6 Quasi-steady-state polarization curves for the oxidation of $\mathrm{HCOOH}$ in $0.5 \mathrm{M} \mathrm{HCOOH}+0.5 \mathrm{M} \mathrm{H}_{2} \mathrm{SO}_{4}$ electrolyte recorded on a Pt-on-Au and Pt electrodes, $\mathbf{b}$ PtAu alloy, and Pt electrodes (c) areaspecific current densities at $0.1 \mathrm{~V}$. Scan rate, $1.0 \mathrm{mV} \mathrm{s}^{-1}$

the electronic structure of $\mathrm{Pt}$ is modified by $\mathrm{Au}$ [41]. While for $\mathrm{Au}$ in $\mathrm{M}-1: 10.22$, its $4 \mathrm{f}_{7 / 2}$ and $4 \mathrm{f}_{5 / 2}$ peaks can be observed at 84.00 and $87.70 \mathrm{eV}$, the same as that of bulk Au due to the scattering dispersion of Pt nanoparticles on the Au substrate [40]. However, as exhibited in Fig. 3, both the peaks of $\mathrm{Au}_{4 \mathrm{f}}$ and of $\mathrm{Pt}_{4 \mathrm{f}}$ in $\mathrm{A}-1: 2.04$ shift to lower binding energies as compared to those of bulk Au and Pt, which indicates that the PtAu in A-1:2.04 catalyst is an alloy [42].

\section{Voltammetric analysis}

Figure 4 shows the cyclic voltammograms (CVs) of pure Pt, Pt-on-Au (Fig. 4a), and PtAu alloy (Fig. 4b) on GCE in deaerated $0.5 \mathrm{M} \mathrm{H}_{2} \mathrm{SO}_{4}$ solution under a scan rate of $50 \mathrm{mV} \mathrm{s}^{-1}$. For Pt/GCE, the curve presents a well-defined hydrogen adsorption/desorption $\left(H_{\mathrm{ads} / \mathrm{des}}\right)$, the broad double layer, and the cathodic reduction peak of Pt oxide in the potential region of $-0.2 \sim 0.1,0.1 \sim 0.28$, and $0.28 \sim 0.9 \mathrm{~V}$, respectively. The CVs of Pt-on-Au and PtAu alloy show the shapes similar to the pure Pt. Moreover, the peaks of $H_{\text {ads/des }}$ are smaller than that on pure Pt and gradually increase with the increase of Pt loadings. It can be observed that the reduction peaks of Pt oxide on both PtAu catalysts shift to a lower potential as the decrease of Pt loading ascribed to the size effect of Pt islands [43]. Additionally, it is noted that the reduction peak of Pt oxide on Pt-on-Au consists of two overlapping peaks when the ratio of $\mathrm{Pt}: \mathrm{Au}$ is larger than 1:5.28, indicating the formation of two different $\mathrm{Pt}$ particles/structures/agglomerates [44, 45]. A similar phenomenon can be seen on the PtAu alloy catalysts with the $\mathrm{Pt} / \mathrm{Au}$ ratio exceeding 0.94:1. When the Pt composition on/in $\mathrm{Au}$ becomes larger, the $H_{\text {ads }} /$ des peaks and the reduction peaks of Pt oxide markedly increase. Kristian [46] pointed out that the Pt entities on the Au surface have more negative potential for the reduction of $\mathrm{Pt}$ oxide at lower $\mathrm{Pt} / \mathrm{Au}$ ratios since it makes obtaining electrons more difficult for Pt atoms compared to higher $\mathrm{Pt} / \mathrm{Au}$ ratios and pure $\mathrm{Pt}$.

\section{Electrooxidation of formic acid}

Figure 5a presents the positive scan CVs of Pt/GCE and Pton-Au catalysts toward FA oxidation in a mixed solution of $0.5 \mathrm{M} \mathrm{HCOOH}$ and $0.5 \mathrm{M} \mathrm{H}_{2} \mathrm{SO}_{4}$. For Pt/GCE, the typical feature of the FA electrooxidation is observed according to the dual-pathway mechanism. As can be seen, a weak peak $\left(\mathrm{O}_{1}\right)$ current density at about $0.3 \mathrm{~V}$ is related to the direct oxidation of FA via the dehydrogenation mechanism, while the other peak $\left(\mathrm{O}_{2}\right)$ at $0.70 \mathrm{~V}$ is due to the oxidation of intermediate $\mathrm{CO}$ generated from the dehydration of FA [47]. Obviously, the peak current density at $\mathrm{O}_{1}\left(j_{\mathrm{O} 1}\right)$ on Pton- $\mathrm{Au}$ is larger, and the peak current density at $\mathrm{O}_{2}\left(j_{\mathrm{O} 2}\right)$ relatively becomes lower than that on pure Pt toward FA oxidation (in Fig. 5a and Table 3), which is in agreement with the results of previous reports [29, 30]. Especially, the M-1:10.22 catalyst of Pt-on-Au shows the highest $j_{\mathrm{O} 1}$ $\left(15.76 \mathrm{~mA} \mathrm{~cm}^{-2}\right)$, which is $\sim 14$ times higher than that of $\mathrm{Pt} / \mathrm{GCE}$. With further decrease of the $\mathrm{Pt} / \mathrm{Au}$ ratios to 1:20.01, the first anodic peak $\left(\mathrm{O}_{1}\right)$ decreases drastically and the second peak $\left(\mathrm{O}_{2}\right)$ almost vanishes. It indicates that FA electrooxidation mainly follows the dehydrogenation pathway on the M-1:10.22 and M-1:20.01 Pt-on-Au catalysts.

The ratio of $j_{\mathrm{O} 1} / j_{\mathrm{O} 2}$ (in Table 3 ) was further used to evaluate the effect of $\mathrm{Pt} / \mathrm{Au}$ composition on FA oxidation pathway. The $j_{\mathrm{O} 1} / j_{\mathrm{O} 2}$ on Pt-on-Au is larger than that on pure $\mathrm{Pt}(0.20)$ and gradually increases as the Pt loadings on $\mathrm{Au}$ surface decrease. It is due to the dehydration pathway on pure 
a

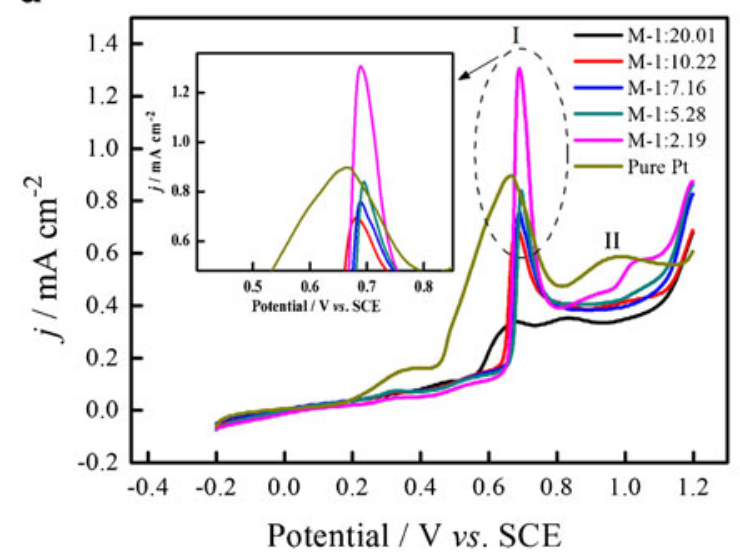

b

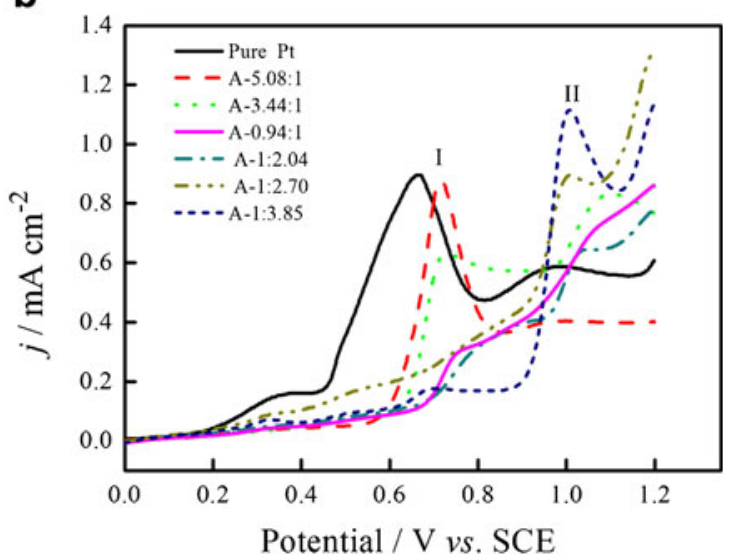

Fig. 7 a $\mathrm{CO}_{\text {ads }}$ stripping voltammograms on M-1:20.01, M-1:10.22, M-1:7.16, M-1:5.28, M-1:2.19, and pure Pt, respectively. b CO $\mathrm{CO}_{\text {ads }}$ stripping voltammograms on pure Pt, A-5.08:1, A-3.44:1, A-0.94:1, A-1:2.04, A-1:2.70, and A-1:3.85, respectively, recorded in $0.5 \mathrm{M} \mathrm{H}_{2} \mathrm{SO}_{4}$ at a scan rate of $20 \mathrm{mV} \mathrm{s}$

Pt or Pt-rich catalyst, leading to the formation of $\mathrm{CO}$ intermediates. When the Pt/Au ratio is below 1:7.16, the pathway of FA oxidation transforms into dehydrogenation. It is in agreement with the observation by Kristian et al. [30] who attributed such to a proposed ensemble effect for Pt-on-Au.

For comparison, Fig. 5b shows the positive scan CVs of $\mathrm{PtAu}$ alloy catalysts for the electrooxidation of FA. A similar phenomenon for FA electrooxidation can be observed on PtAu alloy. Interestingly, the highest $j_{\mathrm{O} 1}$ and $j_{\mathrm{O} 1} / j_{\mathrm{O} 2}$ were obtained on the A-1:2.04 PtAu alloy (6.94 mA cm${ }^{-2}$ ) (Fig. 5b and Table 3), which is different from Pt-on-Au. However, on A-1:2.70 and A-1:3.85, the FA oxidation peak at both $\mathrm{O}_{1}$ and $\mathrm{O}_{2}$ almost vanishes due to the increase of Au. Although a similar dehydrogenation pathway for FA oxidation can be observed on Pt-on-Au (M-1:10.22) and PtAu alloy (A-1:2.04) catalysts, the different $\mathrm{Pt} / \mathrm{Au}$ composition suggests that the electronic structure of PtAu has a significant influence for the FA oxidation pathway, which needs more and further work to study.

As explained earlier, the height of the peak $\mathrm{O}_{1}$ and $\mathrm{O}_{2}$ and their ratio give an indication along which path the reaction is dominant during the electrooxidation of formic acid on the catalyst. Figure $5 \mathrm{c}$, d shows a systematic dependence of these two peaks on the surface composition of Pt-on-Au and PtAu alloy, respectively. At Pt-on-Au surface, peak $\mathrm{O}_{1}$ is the highest at the ratio of $\mathrm{Pt} / \mathrm{Au} \mathrm{1:10.22}$ and decreases with an increase in the ratio of $\mathrm{Pt} / \mathrm{Au}$, while peak $\mathrm{O}_{2}$ height ascends with further increase of Pt loading. For PtAu alloy catalyst, the trend of peak $\mathrm{O}_{1}$ is similar to that of Pt-on-Au catalyst; however, the height of peak $\mathrm{O}_{2}$ starts to descend and would probably reach zero with a decrease in the ratio of $\mathrm{Pt} / \mathrm{Au}$.

To further investigate the kinetics of FA oxidation, Tafel measurements were performed under a steady-state condition. As seen from Fig. 6a, b, the slope of Tafel plots for the $\mathrm{Pt}$-on-Au and PtAu alloy shows a much lower value than that of Pt/GCE (145 mV dec $\left.{ }^{-1}\right)$. Moreover, the M-1:10.22 Pt-on$\mathrm{Au}$ and A-1:2.04 PtAu alloy catalysts show the lowest values of 102 and $114 \mathrm{mV} \mathrm{dec}^{-1}$, respectively. As we have known, the Tafel slope is related to the CO coverage on catalyst, and a lower $\mathrm{CO}$ coverage means a lower Tafel slope value [10, 33]. In addition, Fig. 6c shows the area-specific current densities at $0.1 \mathrm{~V}$ based on the Tafel plots. The activities of Pt-on-Au and PtAu alloy catalysts are much higher than $\mathrm{Pt} / \mathrm{GC}$. Also, the current density for FA oxidation on M1:10.22 Pt-on-Au is about two times higher than that of A1:2.04 PtAu alloy. Compared with Pt/GCE, the lower slopes and the higher current density of both PtAu catalysts are attributed to the low amount of adsorbed $\mathrm{CO}$ or intermediates on the Pt sites. Meanwhile, this result indicates that the $\mathrm{Au}$ atoms of Pt-on-Au nanoparticles are more powerful in improving the electrocatalytic activity toward FA oxidation than those of PtAu alloy particles [33].

$\mathrm{CO}_{\text {ads }}$ stripping voltammetry

The $\mathrm{CO}_{\text {ads }}$ stripping voltammetry measurements were performed on Pt-on-Au (Fig. 7a) and PtAu alloy catalysts on GCE (Fig. 7b) in $0.5 \mathrm{M} \mathrm{H}_{2} \mathrm{SO}_{4}$ solution. As shown in Fig. 7, the pure Pt on GCE presents a typical $\mathrm{CO}_{\mathrm{ads}}$ oxidation peak at $\sim 0.65 \mathrm{~V}$ [43]. For the Pt-on-Au catalysts, the CO stripping peak shifts positively to a higher potential and becomes narrower compared with that on pure Pt. The CO stripping curve of M-1:20.01 Pt-on-Au evolves into a small and broad peak consisting of two poorly separated peaks (a peak at $0.67 \mathrm{~V}$ and a shoulder at $0.83 \mathrm{~V}$ ), indicating that two types of $\mathrm{Pt}$ sites exist on the Au substrate [48]. With the increase of Pt loading on $\mathrm{Au}$ surface, the $\mathrm{CO}$ stripping peaks appear at a lower potential (at $\sim 0.7 \mathrm{~V}$ ) and becomes larger. Yu and coworkers [49] reported similar results and illustrated that the ratio of the isolated single $\mathrm{Pt}$ atom within the $\mathrm{Pt}$ adatom population decided the $\mathrm{CO}$ adsorption on the Pt-modified 
a

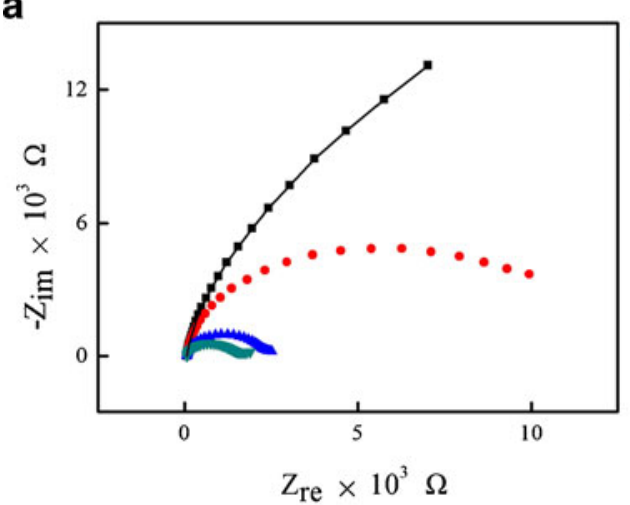

b

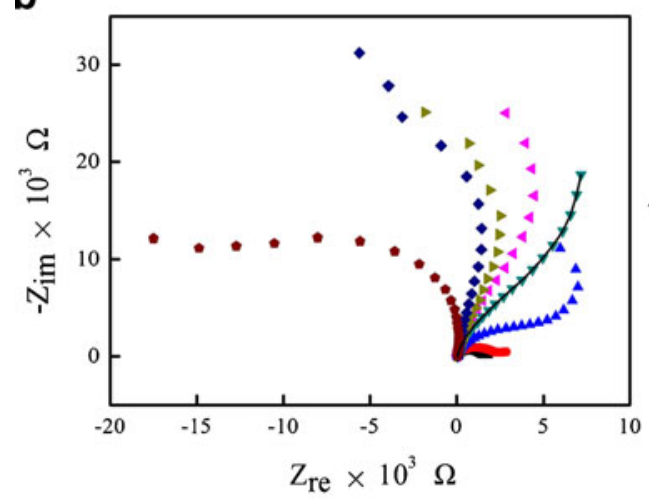

C

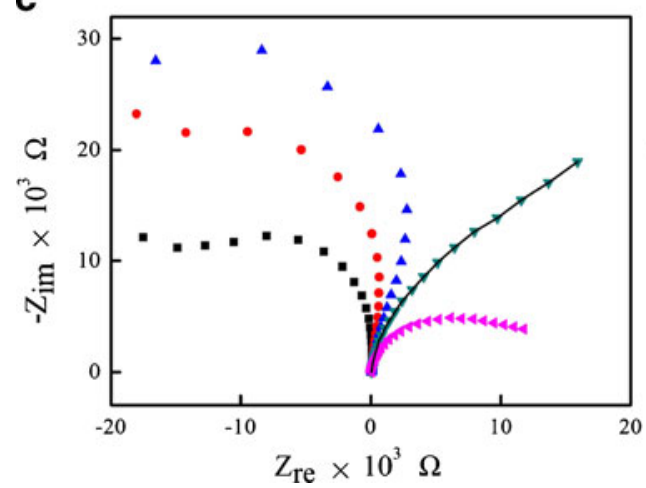

d

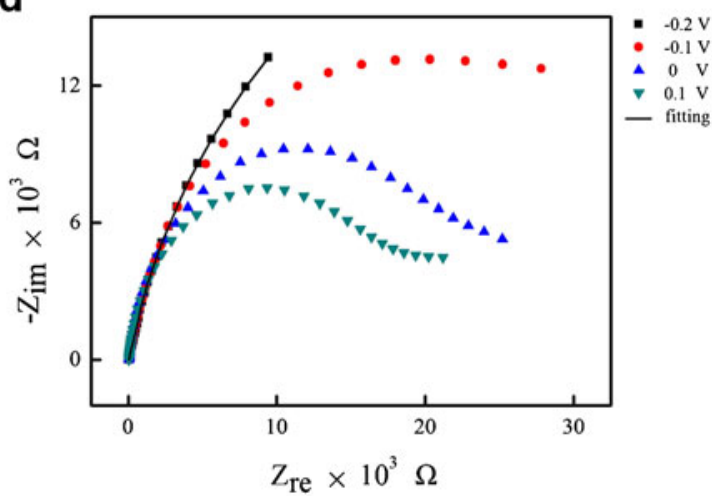

e

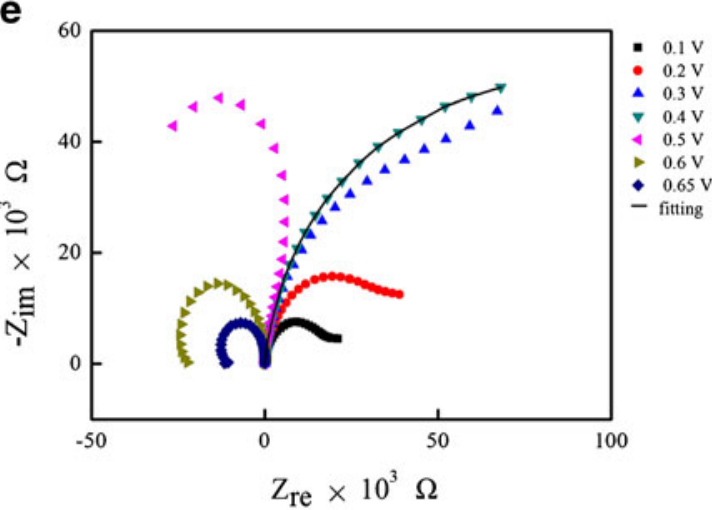

f

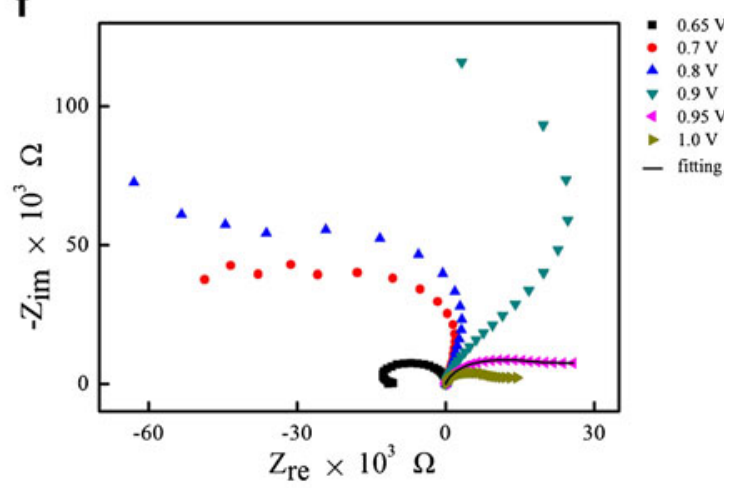

Fig. 8 Nyquist plots of $\mathrm{HCOOH}$ electrooxidation on M-1:10.22 (a-c) and on A-1:2.04 (d-f) electrodes in $0.5 \mathrm{M} \mathrm{HCOOH}^{-} 0.5 \mathrm{M} \mathrm{H}_{2} \mathrm{SO}_{4}$ solution at electrode potentials from $-0.2 \mathrm{~V}$ to $1.0 \mathrm{~V}$

Au surface. The Pt atoms on the Au surface are isolated with lower coverage of $\mathrm{Pt}$, and consequently, the $\mathrm{CO}$ stripping peak shifts negatively owing to the weak $\mathrm{Pt}-\mathrm{CO}$ bond energy compared with pure Pt. Conversely, Pt-Pt neighboring atoms gradually increase with increasing Pt coverage; accordingly, the adsorption of $\mathrm{CO}$ is much stronger than that on bulk Pt, leading the $\mathrm{CO}$ stripping peak to shift positively.

The $\mathrm{CO}_{\text {ads }}$ stripping voltammograms of PtAu alloy (Fig. 7b) are somewhat different from those on Pt-on-Au catalysts. As can be seen from Fig. 7b, the CO stripping peak appears at $0.71 \mathrm{~V}$ (peak I) at the $\mathrm{Pt} / \mathrm{Au}$ ratio of $5.08: 1$, which is $60 \mathrm{mV}$ higher than that of pure Pt. With the ratio of Pt/Au up to 3.44:1, the current density of peak I decreases; however, a new peak (peakII) appears at a more positive potential. Peak I becomes smaller and finally vanishes at a lower $\mathrm{Pt} / \mathrm{Au}$ ratio, indicating a less or no poisoning on PtAu alloy catalyst by $\mathrm{CO}_{\text {ads }}$ with the increasing Au composition [46]. It can be clearly observed that peaks I and II lose their intensity rapidly on the PtAu alloy catalysts $(\mathrm{Pt} / \mathrm{Au}=0.94: 1$ and 1:2.04). However, upon further decreasing the ratio of $\mathrm{Pt} / \mathrm{Au}$ to 1:2.70 and 1:3.85, peak I was not observed, while the intensity of peak II obviously becomes larger. Kristian and co-workers [46] has pointed out that the up-shift in the d-band center of the Pt atoms results in increasing $\mathrm{Pt}-\mathrm{CO}$ bond strength. 
EIS studies for the composite catalysts

Electrochemical impedance spectroscopy as a sensitive and powerful technique has been used to test the catalytic activity of electrocatalyst for FA oxidation. Figure 8 presents the Nyquist plots of formic acid electrooxidation on M-1:10.22 Pt-on-Au and A-1:2.04 PtAu alloy catalysts at various potentials in $0.5 \mathrm{M} \mathrm{HCOOH}+0.5 \mathrm{M} \mathrm{H}_{2} \mathrm{SO}_{4}$ at $0.3 \mathrm{~V}$. When the applied potential is below $0.1 \mathrm{~V}$, the impedance arcs of M1:10 Pt-on-Au are located in the first quadrant, and the diameter of the arcs decreases with increasing electrode potential, as shown in Fig. 8a. This indicates that more active sites are available for formic acid oxidation [50], which coincidentally increases the oxidation current density of formic acid with increasing potential, as shown in Fig. 5. However, with the electrode potential increasing further, the arc diameter increases correspondingly, and interestingly, the arc reverses to the second quadrant (Fig. 8b, c). Such interesting impedance behaviors have also been reported in the studies of methanol or formic acid electrooxidation on Pt or Pt-based alloy electrodes [50-52]. At a positive potential more than $0.95 \mathrm{~V}$, the impedance curves return to normal behaviors in the first quadrant and the arc diameter decreases with the potentials. At these positive potentials, surfaceadsorbed $\mathrm{CO}$ was almost removed completely, which is indicative of the diminishing charge transfer resistance $\left(R_{\mathrm{ct}}\right)$. From Fig. 8d-f, similar features can be also found on A1:2.04 PtAu alloy, except that the arc diameter is substantially larger than that on M-1:10.22 Pt-on-Au catalyst, indicating a higher $R_{\mathrm{ct}}$ for formic acid oxidation on A-1:2.04 PtAu alloy catalyst. This coincides with the results of the aforementioned $\mathrm{CV}$ in Fig. 5 wherein the catalytic activity of M-1:10.22 is higher than that of A-1:2.04 for formic acid electrooxidation.

\section{Conclusions}

In the present work, PtAu catalysts with various $\mathrm{Pt} / \mathrm{Au}$ ratios obtained by electrodeposition of Pt precursor on preprepared $\mathrm{Au}$ nanoparticles (Pt-on-Au) and by simultaneous co-electrodeposition of $\mathrm{Au}$ and $\mathrm{Pt}$ (PtAu alloy) have been investigated as an anodic electrocatalyst toward formic acid and carbon monoxide oxidation. The two types of PtAu catalysts show a higher electrocatalytic activity toward formic acid oxidation compared to pure Pt on GCE. The $\mathrm{Au}$ atoms in PtAu catalysts promote the activity of formic acid electrooxidation. The highest activities under potentiodynamic and quasi-steady-state condition were obtained on M-1:10.22 Pt-on-Au and on A-1:2.04 PtAu alloy, respectively. The results of $\mathrm{CO}_{\text {ads }}$ stripping experiment show that the $\mathrm{CO}$ stripping peak position shifts positively on the two types of PtAu nanoparticles compared with that of the Pt catalyst. Moreover, EIS data indicate that the performance of M-1:10.22 Pt-on-Au for formic acid electrooxidation is much better than that of A-1:2.04 PtAu alloy.

Acknowledgments This work was supported by the National Natural Science Foundation of China (Grant Nos. 51073114, 20933007, 21173261, 51073074, and 50963002), the Academic Award for Young Graduate Scholar of Soochow University, the Opening Project of Xinjiang Key Laboratory of Electronic Information Materials and Devices (XJYS0901-2010-01), and the Priority Academic Program Development of Jiangsu Higher Education Institutions (PAPD).

Open Access This article is distributed under the terms of the Creative Commons Attribution License which permits any use, distribution, and reproduction in any medium, provided the original author(s) and the source are credited.

\section{References}

1. Raoof JB, Ojani R, Sahar RN (2010) Electrochemical synthesis of bimetallic Au@Pt nanoparticles supported on gold film electrode by means of self-assembled monolayer. Int J Hydrog Energy 641:71-77

2. Habibi B, Delnavaz N (2010) Electrocatalytic oxidation of formic acid and formaldehyde on platinum nanoparticles decorated carbonceramic substrate. Int J Hydrog Energy 35:8831-8840

3. Raoof JB, Karimi MA, Hosseini SR, Mangelizade S (2011) Enhanced electrocatalytic activity of nickel particles electrodeposited onto poly ( $m$-toluidine) film prepared in presence of CTAB surfactant on carbon paste electrode for formaldehyde oxidation in alkaline medium. Int J Hydrog Energy 36:13281-13287

4. Zhu M, Lu Y, Du Y, Li J, Wang X, Yang P (2011) Photocatalytic hydrogen evolution without an electron mediator using a porphyrinpyrene conjugate functionalized Pt nanocomposite as a photocatalyst. Int J Hydrog Energy 36:4298-4304

5. Belousov OV, Belousova NV, Sirotina AV, Solovyov LA, Zhyzhaev AM, Zharkov SW, Mikhlin YL (2011) Formation of bimetallic $\mathrm{Au}-\mathrm{Pd}$ and $\mathrm{Au}-\mathrm{Pt}$ nanoparticles under hydrothermal conditions and microwave irradiation. Langmuir 27:11697-11703

6. Yao Z, Zhu M, Jiang F, Du Y, Wang C, Yang P (2012) Highly efficient electrocatalytic performance based on Pt nanoflowers modified reduced graphene oxide/carbon cloth electrode. J Mater Chem 22:13707-13713

7. Maye MM, Kariuki NN, Luo J, Han L, Njoki P, Wang L, Lin Y, Naslund HR, Zhong C (2004) Electrocatalytic reduction of oxygen: gold and gold-platinum nanoparticle catalysts prepared by twophase protocol. Gold Bull 37:217-223

8. Rice C, Ha S, Masel RI, Waszczuk P, Wieckowski A, Barnard T (2002) Direct formic acid fuel cells. J Power Sources 111:83-89

9. Wang X, Hu J, Hsing IM (2004) Electrochemical investigation of formic acid electro-oxidation and its crossover through a Nafion ${ }^{\circledR}$ membrane. J Electroanal Chem 562:73-80

10. Habibi B, Gahramanzadeh R (2011) Fabrication and characterization of non-platinum electrocatalyst for methanol oxidation in alkaline medium: nickel nanoparticles modified carbon-ceramic electrode. Int J Hydrog Energy 36:1913-1923

11. Park S, Xie Y, Weaver MJ (2002) Electrocatalytic pathways on carbon-supported platinum nanoparticles: comparison of particlesize-dependent rates of methanol, formic acid, and formaldehyde electrooxidation. Langmuir 18:5792-5798

12. Chang SC, Leung LWH, Weaver MJ (1990) Metal crystallinity effects in electrocatalysis as probed by real-time FTIR spectroscopy: electrooxidation of formic acid, methanol, and ethanol on ordered low-index platinum surfaces. J Phys Chem 94:6013-6021 
13. Chen G, Li Y, Wang D, Zheng L, You G, Zhong C, Yang L, Cai F, Cai J, Chen B (2011) Carbon-supported PtAu alloy nanoparticle catalysts for enhanced electrocatalytic oxidation of formic acid. $\mathrm{J}$ Power Sources 196:8323-8330

14. Rigsby MA, Zhou W, Lewera A, Duong HT, Bagus PS, Jaegermann W, Hunger R (2008) Experiment and theory of fuel cell catalysis: methanol and formic acid decomposition on nanoparticle Pt/Ru. J Phys Chem C 112:15595-15601

15. Mazumder V, Lee Y, Sun S (2010) Recent development of active nanoparticle catalysts for fuel cell reactions. Adv Funct Mater 20:1224-1231

16. Zhang H, Jin M, Xia Y (2012) Enhancing the catalytic and electrocatalytic properties of Pt-based catalysts by forming bimetallic nanocrystals with Pd. Chem Soc Rev 41:8035-8049

17. Kang S, Lee J, Lee JK, Chung S, Tak Y (2006) Influence of bimodification of $\mathrm{Pt}$ anode catalyst in direct formic acid fuel cells. J Phys Chem B 110:7270-7274

18. Lee H, Habas SE, Somorjai GA, Yang P (2008) Localized Pd overgrowth on cubic Pt nanocrystals for enhanced electrocatalytic oxidation of formic acid. J Am Chem Soc 130:5406-5407

19. Schmidt TJ, Behm RJ (2000) Formic acid oxidation on pure and bimodified Pt(111): temperature effects. Langmuir 16:8159-8166

20. Choi JH, Jeong KJ, Dong Y, Han J, Lim TH, Lee JS, Sung YE (2006) Electro-oxidation of methanol and formic acid on PtRu and PtAu for direct liquid fuel cells. J Power Sources 163:71-75

21. Xu J, Zhao T, Liang Z (2008) Carbon supported platinum-gold alloy catalyst for direct formic acid fuel cells. J Power Sources 185:857-861

22. Jia J, Cao L, Wang Z (2008) Platinum-coated gold nanoporous film surface: electrodeposition and enhanced electrocatalytic activity for methanol oxidation. Langmuir 24:5932-5936

23. Zhang Y, Huang Q, Zou Z, Yang J, Vogel W, Yang H (2010) Enhanced durability of Au cluster decorated $\mathrm{Pt}$ nanoparticles for the oxygen reduction reaction. J Phys Chem C 114:6860-6868

24. Luo J, Njoki PN, Lin Y, Mott D, Wang L, Zhong C (2006) Characterization of carbon-supported AuPt nanoparticles for electrocatalytic methanol oxidation reaction. Langmuir 22:2892-2898

25. Kim S, Jung C, Kim J, Rhee CK, Choi SM, Lim TH (2010) Modification of $\mathrm{Au}$ nanoparticles dispersed on carbon support using spontaneous deposition of Pt toward formic acid oxidation. Langmuir 26:4497-4505

26. Zhang J, Sasaki K, Sutter E, Adzic RR (2007) Stabilization of platinum oxygen-reduction electrocatalysts using gold clusters. Science 315:220-222

27. Habrioux A, Vogel W, Guinel M, Guetaz L, Servat K, Kokoh B, Alonso-Vante N (2009) Structural and electrochemical studies of Au-Pt nanoalloys. Phys Chem Chem Phys 11:3573-3579

28. Malaknaz ME, Mehran M, Bineta K, Louis N, Patricia K, Hynd R (2010) Bimetallic Au-Pt nanoparticles synthesized by radiolysis: application in electro-catalysis. Gold Bull 43:49-56

29. Wang R, Wang C, Cai W, Ding Y (2010) Ultralow-platinumloading high-performance nanoporous electrocatalysts with nanoengineered surface structures. Adv Mater 22:1845-1848

30. Kristian N, Yan Y, Wang X (2008) Highly efficient submonolayer Pt-decorated Au nano-catalysts for formic acid oxidation. Chem Commun 0:353-355

31. Ren B, Lian X, Li J, Fang P, Lai Q, Tian Z (2008) Spectroelectrochemical flow cell with temperature control for investigation of electrocatalytic systems with surface-enhanced Raman spectroscopy. Faraday Discuss 140:155-165

32. Liu C, Wei Y, Liu C, Wang K (2012) Pt-Au core/shell nanorods: preparation and applications as electrocatalysts for fuel cells. J Mater Chem 22:4641-4644

33. Park IS, Lee KS, Choi JH, Park HY, Sung YE (2007) Surface structure of Pt-modified Au nanoparticles and electrocatalytic activity in formic acid electro-oxidation. J Phys Chem C 111:126-133
34. Liu J, Cao L, Huang W, Li Z (2011) Preparation of AuPt alloy foam films and their superior electrocatalytic activity for the oxidation of formic acid. ACS Appl Mater Interfaces 3:3552-3558

35. Huang J, Hou H, You T (2009) Highly efficient electrocatalytic oxidation of formic acid by electrospun carbon nanofiber-supported $\mathrm{Pt}_{x} \mathrm{Au}_{100}$ ${ }_{-x}$ bimetallic electrocatalyst. Electrochem Commun 11:1281-1284

36. Zhang G, Zhao D, Feng Y, Zhang B, Su D, Liu G, Xu B (2012) Catalytic Pt-on-Au nanostructures: why Pt becomes more active on smaller Au particles. ACS Nano 6:2226-2236

37. Luo M, Wang C, Hu G, Lin W, Ho C, Lin Y, Hsu Y (2009) Active alloying of $\mathrm{Au}$ with $\mathrm{Pt}$ in nanoclusters supported on a thin film of $\mathrm{Al}_{2} \mathrm{O}_{3} / \mathrm{NiAl}(100)$. J Phys Chem C 113:21054-21062

38. Hu Y, Zhang H, Wu P, Zhang H, Zhou B, Cai C (2011) Bimetallic $\mathrm{Pt}-\mathrm{Au}$ nanocatalysts electrochemically deposited on graphene and their electrocatalytic characteristics towards oxygen reduction and methanol oxidation. Phys Chem Chem Phys 13:4083-4094

39. Mott D, Luo J, Njoki PN, Lin Y, Wang L, Zhong C (2007) Synergistic activity of gold-platinum alloy nanoparticle catalysts. Catal Today 122:378-385

40. Moulder JF, Stickle WF, Sobol PE, Bomben KD (1995) Handbook of x-ray photoelectron spectroscopy. Physical Electronics, Inc., Eden Prairie, MN

41. Xu YY, Dong YN, Shi J, Xu ML, Zhang ZF, Yang XK (2011) $\mathrm{Au} @$ Pt core-shell nanoparticles supported on multiwalled carbon nanotubes for methanol oxidation. Catal Commun 13:54-58

42. Yi CW, Luo K, Wei T, Goodman DW (2005) The composition and structure of Pd-Au surfaces. J Phys Chem B 109:18535-18540

43. Arenz M, Mayrhofer KJJ, Stamenkovic V, Blizanac BB, Tomoyuki T, Ross PN, Markovic NM (2005) The effect of the particle size on the kinetics of $\mathrm{CO}$ electrooxidation on high surface area Pt catalysts. J Am Chem Soc 127:6819-6829

44. Xia Y, Liu J, Huang W, Li Z (2012) Electrochemical fabrication of clean dendritic $\mathrm{Au}$ supported Pt clusters for electrocatalytic oxidation of formic acid. Electrochim Acta 70:304-312

45. Scheijen FJE, Beltramo GL, Hoeppener S, Housmans THM, Koper MTM (2008) The electrooxidation of small organic molecules on platinum nanoparticles supported on gold: influence of platinum deposition procedure. J Solid State Electrochem 12:483-495

46. Kristian N, Yu Y, Gunawan P, Xu R, Deng W, Liu X, Wang X (2009) Controlled synthesis of Pt-decorated Au nanostructure and its promoted activity toward formic acid electro-oxidation. Electrochim Acta 54:4916-4924

47. Obradović MD, Rogan JR, Babić BM, Tripković AV, Gautam ARS, Radmilović VR, Gojković SL (2012) Formic acid oxidation on Pt$\mathrm{Au}$ nanoparticles: relation between the catalyst activity and the poisoning rate. J Power Sources 197:72-79

48. Du B, Tong Y (2005) A coverage-dependent study of Pt spontaneously deposited onto $\mathrm{Au}$ and $\mathrm{Ru}$ surfaces: direct experimental evidence of the ensemble effect for methanol electro-oxidation on Pt. J Phys Chem B 109:17775-17780

49. Yu Y, Lim KH, Wang JY, Wang X (2012) CO adsorption behavior on decorated Pt@Au nanoelectrocatalysts: a combined experimental and DFT theoretical calculation study. J Phys Chem C 116:3851-3856

50. Yue R, Jiang F, Du Y, Xu J, Yang P (2012) Electrosynthesis of a novel polyindole derivative from 5 -aminoindole and its use as catalyst support for formic acid electrooxidation. Electrochim Acta 77:29-38

51. Chen W, Kim J, Sun S, Chen S (2006) Electro-oxidation of formic acid catalyzed by FePt nanoparticles. Phys Chem Chem Phys 8:2779-2786

52. Chen W, Kim J, Sun S, Chen S (2007) Composition effects of FePt alloy nanoparticles on the electro-oxidation of formic acid. Langmuir 23:11303-11310 